\title{
New equation to predict size-resolved gas-particle partitioning quotients for polybrominated diphenyl ethers
}

\author{
Peng-Tuan $\mathrm{Hu}^{\mathrm{a}, \mathrm{b}, \mathrm{c}}$, Peng-Hao Su ${ }^{\mathrm{d}}$, Wan-Li Ma ${ }^{\mathrm{a}, \mathrm{b}, \mathrm{c}}$, Zi-Feng Zhang ${ }^{\mathrm{a}, \mathrm{b}, \mathrm{c}}$, Li-Yan Liu ${ }^{\mathrm{a}, \mathrm{b}, \mathrm{c}}$, \\ Wei-Wei Song, ${ }^{\mathrm{a}, \mathrm{b}, \mathrm{c}}$, Li-Na Qiao ${ }^{\mathrm{a}, \mathrm{b}, \mathrm{c}}$, Chong-Guo Tian ${ }^{\mathrm{e}}$, Robie W. Macdonald ${ }^{\mathrm{f}}$, Anatoly Nikolaev ${ }^{\mathrm{g}}$, \\ Zhi-Guo Cao ${ }^{\mathrm{h}}$, Yi-Fan $\mathrm{Li}^{\mathrm{a}, \mathrm{b}, \mathrm{c}, \mathrm{i}, *}$

\footnotetext{
${ }^{a}$ International Joint Research Center for Persistent Toxic Substances (IJRC-PTS), State Key Laboratory of Urban Water Resource and Environment, Harbin Institute of Technology (HIT), Harbin, 150090, PR China

${ }^{\mathrm{b}}$ International Joint Research Center for Arctic Environment and Ecosystem (IJRC-AEE), Polar Academy, HIT (PA-HIT), Harbin, 150090, PR China

${ }^{\mathrm{c}}$ Heilongiiang Provincial Key Laboratory of Polar Environment and Ecosystem (HPKL-PEE), School of Environment, HIT, Harbin, 150090, PR China

${ }^{\mathrm{d}}$ Department of Environmental Engineering, Shanghai Maritime University, Shanghai, 201306, PR China

${ }^{\mathrm{e}}$ Yantai Institute of Coastal Zone Research, Chinese Academy of Sciences, PR China

${ }^{\mathrm{f}}$ Institute of Ocean Sciences, Department of Fisheries and Oceans, P.O. Box 6000, Sidney, BC, V8L 4B2, Canada

${ }^{\mathrm{g}}$ Institute of Natural Sciences, North-Eastern Federal University, Russia

${ }^{\mathrm{h}}$ School of Environment, Key Laboratory for Yellow River and Huai River Water Environment and Pollution Control, Ministry of Education, Henan Normal University, Xinxiang, Henan, 453007, PR China
} \\ ${ }^{\mathrm{i}}$ IJRC-PTS-NA, Toronto, Ontario, M2N 6X9, Canada
}

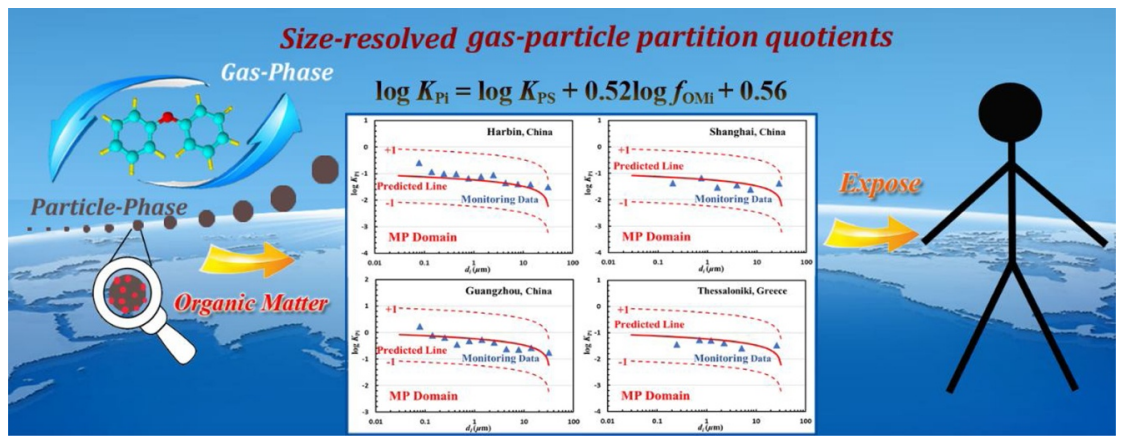

Abbreviations: SVOCs, semi-volatile organic compounds; G/P, gas/particle; PBDEs, polybrominated diphenyl ethers; OCPs, organic chlorine pesticides; PCDD/Fs, polychlorinated dibenzo-p-dioxins and dibenzofurans; PAHs, polycyclic aromatic hydrocarbons; PCB, polychlorinated biphenyls; MOUDI, Micro-Orifice Uniform Deposit Impactor; GFF, glass fiber filter; PUF, polyurethane foam; ADR, acceptable deviation range; ED, Exposure dose; ICRP, International Commission on Radiological Protection; $K_{\mathrm{OA}}$, octanol-air partitioning coefficients; $P_{\mathrm{L}}$, sub-cooled liquid vapor pressures; $C_{\mathrm{P}}$, concentrations of SVOCs in TSP; $C_{\mathrm{G}}$, concentrations of SVOCs in gas phase; TSP, total suspended particles; TSP, concentrations of total suspended particles; $C_{\mathrm{P}}$, concentrations of SVOCs in particles with size-range $i$; $P M_{\mathrm{i}}$, concentrations of particles with size-range $i$; $R_{\mathrm{CP}}$, size-distribution of SVOCs; $R_{\mathrm{PMi}}$, size-distribution of particles; $K_{\mathrm{P}}$, gas/particle partition quotients of SVOCs for bulk air; $K_{\mathrm{Pi}}$, gas/particle partition quotients of SVOCs for size-segregated particles; $f_{\mathrm{OM}}$, organic matter content of bulk particles; $f_{\mathrm{OMi}}$, organic matter contents of sizesegregated particles; $K_{\mathrm{PS}}$, gas/particle partition quotients of SVOCs for bulk air under steady state; $K_{\mathrm{P}-\mathrm{HB}}$, gas/particle partition quotients of SVOCs for bulk air by

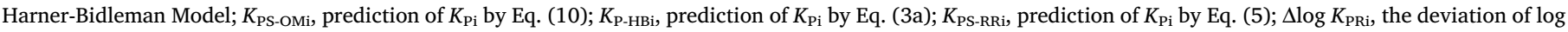
$K_{\mathrm{Pi}}$ from $\log K_{\mathrm{PS}}$ as a function of $\log \left(R C_{\mathrm{Pi}} / R_{\mathrm{PMi}}\right) ; \Delta \log K_{\mathrm{POMi}}$, the deviation of $\log K_{\mathrm{Pi}}$ from $\log K_{\mathrm{PS}}$ as a function of $\log f_{\mathrm{OMi}} ; \Delta \log K_{\mathrm{PHBi}}$, the deviation of $\log K_{\mathrm{Pi}}$ from $\log K_{\mathrm{P}-\mathrm{HB}}$

* Corresponding author at: International Joint Research Center for Persistent Toxic Substances (IJRC-PTS), State Key Laboratory of Urban Water Resource and Environment, Harbin Institute of Technology, 73 Huanghe Road, Nangang District, Harbin, 150090, Heilongjiang, PR China.

E-mail address: ijrc_pts_paper@yahoo.com (Y.-F. Li). 
A R T I C L E I N F O

Editor: T. Meiping

Keywords:

Size-segregated

Gas/particle partition

Polybrominated diphenyl ethers

Healthy exposure

\begin{abstract}
A B S T R A C T
Gas/particle (G/P) partition quotients of semi-volatile organic compounds (SVOCs) for bulk air have been widely discussed in experimental and theoretical contexts, but research on size-resolved G/P partition quotients ( $K_{\mathrm{Pi}}$ ) are scarce and limited in scope. To investigate G/P partition behavior of polybrominated diphenyl ethers (PBDEs) for size-segregated particles in the atmosphere, 396 individual size-segregated particulate samples (36 batches $\times 11$ size-ranges), and 108 pairs of concurrent gaseous and bulk particulate samples were collected in Harbin, China. A steady-state equation based on bulk particles is derived to determine G/P partition quotients of PBDEs for size-segregated particles, which depends on the organic matter contents of size-segregated particles $\left(f_{\mathrm{OMi}}\right)$. This equation can well predict $K_{\mathrm{Pi}}$ with knowledge of bulk partition quotient $\left(K_{\mathrm{PS}}\right)$, ambient temperature, and $f_{\mathrm{OMi}}$, the results of which match well with monitoring data in Harbin and other published data collected in Shanghai and Guangzhou of China and Thessaloniki of Greece, and remedies a defect of over-estimate $K_{\mathrm{Pi}}$ for high-brominated PBDEs by the previous equation. In particular, the new equation contributes to obtaining the PBDEs concentrations in all atmospheric phase from partial phase, then provides a credible path to evaluate healthy exposure dose from the airborne PBDEs, by co-utilization with exposure models.
\end{abstract}

\section{Introduction}

Semi-volatile organic compounds (SVOCs) a class of global and ubiquitous pollutions, such as organic chlorine pesticides (OCPs), plasticizers (phthalates), fire retardants, which are highly toxic and bioaccumulative, thus damaging the health of both wildlife and human beings (Chen et al., 2019; Covaci et al., 2006; Czub and McLachlan, 2004; Guo et al., 2020; Li et al., 2013; Liu et al., 2019; Pan et al., 2009). Gas/particle (G/P) partitioning behavior can govern the fate of SVOCs in the atmosphere, thus affecting the scope and efficiency of long-range atmospheric transport (Bidleman, 1988; Gotz et al., 2008; Lohmann et al., 2000). Meanwhile, gaseous and particulate SVOCs can enter human body with breathing and other routes, thus the G/P partition also has an important influence on human health (Cao et al., 2018b; Lao et al., 2018; Weschler et al., 2015; Zhang et al., 2017).

The G/P partitioning behavior for bulk particles has been studied for decades, and several models have been developed to predict the partitioning behavior for SVOCs between gas phase and bulk particles; these include the Harner-Bidleman model (Harner and Bidleman, 1998), Junge-Pankow model (Pankow, 1987), and poly-parameter linear free energy relationships model (Goetz et al., 2007). These models all assume equilibrium conditions. Recently, two newly developed models, the Li-Jia empirical model (Li and Jia, 2014) and the LiMa-Yang model (Li et al., 2015), which have been derived without assuming equilibrium (Qiao et al., 2019), perform well in predicting the partitioning behavior for polybrominated diphenyl ethers (PBDEs) (Li et al., 2016b, 2017; Li et al., 2015), non-PBDE brominated flame retardants (Li et al., 2016a), polychlorinated dibenzo-p-dioxins and dibenzofurans (PCDD/Fs) (Cao et al., 2018a), and organic chlorine pesticides (OCPs) (Qiao et al., 2019).

In nature, atmospheric particles exhibit a wide range of sizes, where the concentrations of SVOCs vary, with fine particles $(<0.49 \mu \mathrm{m}$ or around $1 \mu \mathrm{m}$ (Besis et al., 2015, 2017; Luo et al., 2014; Lyu et al., 2016; Mandalakis et al., 2009; Su et al., 2018)) accounting for most of the concentration. Several research groups have studied the distributions of SVOCs in the size-segregated particles, most of them targeting polycyclic aromatic hydrocarbons (PAHs) (Chrysikou et al., 2009; Degrendele et al., 2014; Gutierrez-Daban et al., 2005; Kaupp and McLachlan, 1999; Oliveira et al., 2011; Venkataraman et al., 1999; Yu and Yu, 2012), PCDD/Fs (Degrendele et al., 2014; Kaupp and McLachlan, 1999; Lee et al., 2008), PBDEs (Besis et al., 2015, 2017; Luo et al., 2014; Lyu et al., 2016; Mandalakis et al., 2009; Okonski et al., 2014; Su et al., 2018; Zhang et al., 2012), polychlorinated biphenyls (PCBs) (Chrysikou et al., 2009; Degrendele et al., 2014), and OCPs (Chrysikou et al., 2009). Therefore, the G/P partitioning behavior of SVOCs varies among particle sizes, which implies that size-resolved G/P partitioning behavior of SVOCs would be different than partitioning behavior for bulk particles (de la Torre et al., 2018; Jin et al., 2017b;
Offenberg and Baker, 2002; Venkataraman et al., 1999).

A few scientists have studied the G/P partitioning quotients of SVOCs between gas and size-resolved particles. Venkataraman et al. (1999) developed equations for size-resolved G/P partitioning coefficients for PAHs, based on adsorption (Pankow, 1987) and absorption models (Finizio et al., 1997; Harner and Bidleman, 1998) under equilibrium state. Offenberg and Baker (2002) and Lee et al. (2008) have applied several G/P partition models for bulk particles under equilibrium to predict the size-resolved G/P partition for PAHs and PPCD/Fs. Similar to Venkataraman et al. (1999), Lyu et al. (2016) have applied the same equations to calculate size-resolved gas/particle partitioning quotients for PBDEs.

A common treatment in developing the size-resolved G/P partition equations or applying the bulk-particle models for size-resolved G/P partitioning equations, is to start with the equilibrium models for bulk particles and change the bulk parameters to parameters for individual particle sizes. It is commonly recognized that equilibrium-based G/P partitioning equations do not work well for SVOCs with high octanolair partitioning coefficients $\left(K_{\mathrm{OA}}\right)$ or low sub-cooled liquid vapor pressures $\left(P_{\mathrm{L}}\right)$, conditions that apply to, for example, high molecular weight PBDEs (Li et al., 2017, 2015). Thus, equations developed from equilibrium-based bulk particle models should not be expected to perform well for size-resolved particles for these types of SVOCs, especially for PBDEs (Offenberg and Baker, 2002; Lee et al., 2008; Lyu et al., 2016).

In this study, we (1) investigate G/P partitioning behavior of PBDEs for both bulk and size-resolved particles both theoretically and by reference to monitoring data; (2) derive equations to predict size-resolved G/P partitioning quotients for PBDEs; (3) verify the derived equations using monitoring data collected by our group and by others with the comparison to other available size-resolved G/P partitioning equations.

\section{Experimental methods}

\subsection{Sample collection and experiment}

A medium-volume sampler (TE-1000X, Tisch environmental Inc., USA) and a Micro-Orifice Uniform Deposit Impactor (MOUDI, Model 110, MSP Corporation, USA) were deployed close to each other on the campus of Harbin Institute of Technology (HIT), Harbin, China (Figure A.1) to collect air samples simultaneously (sampling dates and temperatures are listed in Table A.1 \& A.2). Using these two samplers, we collected gaseous and bulk particulate samples using the medium-volume sampler (equipped with a glass fiber filter (GFF) followed by a polyurethane foam (PUF) plug) and size-segregated samples using the MOUDI sampler (equipped with 11 quartz fiber filters to 11 sizestages: $>18 \mu \mathrm{m}, 10-18 \mu \mathrm{m}, 5.6-10 \mu \mathrm{m}, 3.2-5.6 \mu \mathrm{m}, 1.8-3.2 \mu \mathrm{m}, 1-1.8$ $\mu \mathrm{m}, 0.56-1 \mu \mathrm{m}, 0.32-0.56 \mu \mathrm{m}, 0.18-0.32 \mu \mathrm{m}, 0.1-0.18 \mu \mathrm{m}$ and 
$0.056-0.1 \mu \mathrm{m})$. Samples were collected synchronously at ambient air temperature, which ranged from $-28.3^{\circ} \mathrm{C}$ to $32.0^{\circ} \mathrm{C}$. All told, 36 batches of size-segregated samples (11 size-segregated samples for each batch) and 108 pairs of GFF and PUF samples were obtained. Three batches of the 36 size-segregated samples were used to determine the organic matter content. Three contiguous batches collected under similar ambient temperatures were combined for the remaining 33 batches of the size-segregated samples along with the corresponding three pairs of air and bulk particle samples, to produce 11 groups of pooled samples for measuring the PBDE concentrations.

The details of experimental methods are listed in Section A.1 - A.3. In brief, the fractions of organic carbon of the 36 size-segregated samples were measured at Yantai Institute of Coastal Zone Research, Chinese Academy of Science using a Desert Research Institute (DRI) Model 2001 Carbon analyzer (Atmoslytic Inc., Calabasas, CA) following the Interagency Monitoring of Protected Visual Environment (IMPROVE) thermal/optical reflectance (TOR) protocol. The fraction of organic matter $\left(f_{\mathrm{OM}}\right)$ was estimated to be 1.4 times the fraction of organic carbon. The fraction of organic matter $\left(f_{\mathrm{OM}}\right)$ was estimated to be 1.4 times the fraction of organic carbon. To measure PBDEs, samples were extracted, purified and analyzed at the Laboratory of the International Joint Research Center for Persistent Toxic Substances (IJRCPTS), HIT. Eight PBDE congeners (BDE-17, -28, -47, -66, -99, -138, -183, and BDE-209) were quantified using an Agilent 7890B gas chromatograph (column: DB-5MS, $15 \mathrm{~m} \times 0.25 \mathrm{~mm} \times 0.1 \mathrm{~mm}$, Agilent) coupled with a 5977A mass spectrometer in negative chemical ionization mode.

\subsection{Equations}

The bulk G/P partitioning quotient, $K_{\mathrm{P}}\left(\mathrm{m}^{3} / \mu \mathrm{g}\right)$, is defined as (Yamasaki et al., 1982; Pankow, 1991):

$K_{\mathrm{P}}=\left(C_{\mathrm{P}} / \mathrm{TSP}\right) / C_{\mathrm{G}}$

where $C_{\mathrm{G}}$ and $C_{\mathrm{P}}$ (both in $\mathrm{pg} / \mathrm{m}^{3}$ of air) are the concentrations of SVOCs for gas and bulk particle phases in the atmosphere, respectively, and TSP is the concentration of total suspended particles $\left(\mu \mathrm{g} / \mathrm{m}^{3}\right.$ air) in air. Similar to the Eq. (1), the G/P partitioning quotients of SVOCs in the range of size-range $i, K_{\mathrm{Pi}}\left(\mathrm{m}^{3} / \mu \mathrm{g}\right)$, is defined as (Offenberg and Baker, 2002):

$K_{\mathrm{Pi}}=\left(C_{\mathrm{Pi}} / P M_{\mathrm{i}}\right) / C_{\mathrm{G}}$

where $C_{\mathrm{Pi}}$ is the concentration of particulate SVOCs in the particle sizerange $i$ (in $\mathrm{pg} / \mathrm{m}^{3}$ air), and $P M_{\mathrm{i}}\left(\mu \mathrm{g} / \mathrm{m}^{3}\right.$ air) is the concentration of particles in the size-range $i$.

Lyu et al. (2016) developed an equation to calculate the size-resolved G/P partitioning quotients of PBDEs for the absorption process,

$\log K_{\mathrm{P}-\mathrm{HBi}}=\log K_{\mathrm{OA}}+\log f_{\mathrm{OMi}}-11.91$

where $f_{\text {OMi }}$ is the organic matter content of particles in the size-range $i$. This equation is derived from the Harner-Bidleman Equation (Harner and Bidleman, 1998),

$\log K_{\mathrm{P}-\mathrm{HB}}=\log K_{\mathrm{OA}}+\log f_{\mathrm{OM}}-11.91$

by replacing $f_{\mathrm{OM}}$, the organic matter content of bulk particles, with $f_{\mathrm{OMi}}$. The value of $\log K_{\mathrm{OA}}$ can be calculated from sampling data at ambient temperatures ( $T$, unit $K$ ) by using,

$\log K_{\mathrm{OA}}=A_{\mathrm{O}}+B_{\mathrm{O}} / T$

where $A_{\mathrm{O}}$ and $B_{\mathrm{O}}$, the Clausius-Clapeyron coefficients, can be found for the selected PBDE congeners in Table A.3 (Yang et al., 2018).

It has been usually recognized that the equilibrium-based G/P partitioning equations do not work well for high values of $K_{\mathrm{OA}}$, as is the case for high molecular weight PBDEs (Li et al., 2017, 2015). Thus, the above equations developed for size-segregated particles should not be expected to work well under high $K_{\mathrm{OA}}$ conditions generally, and for PBDEs in particular. We therefore derive new G/P partitioning equations for PBDEs distributed on size-segregated particles using a steadystate assumption as follows. Dividing Eq. (1) by Eq. (2) leads to

$\log K_{\mathrm{Pi}}=\log K_{\mathrm{PS}}+\Delta \log K_{\mathrm{PRi}}$

where $\Delta \log K_{\mathrm{PRi}}$ is the deviation of $\log K_{\mathrm{Pi}}$ from the bulk $\log K_{\mathrm{PS}}$, the logarithm of the bulk $\mathrm{G} / \mathrm{P}$ quotients under steady state conditions, as a function of $\log \left(R_{\mathrm{CPi}} / R_{\mathrm{PMi}}\right)$, given by

$\Delta \log K_{\mathrm{PRi}}=\log \left(R_{\mathrm{CPi}} / R_{\mathrm{PMi}}\right)$.

Here, the size-distribution of PBDEs $\left(R_{\mathrm{CPi}}\right)$ is given by

$R_{\mathrm{CPi}}=C_{\mathrm{Pi}} / C_{\mathrm{P}}$

and the size-distribution of particles $\left(R_{\mathrm{PMi}}\right)$ is

$R_{\mathrm{PMi}}=P M_{\mathrm{i}} / T S P$.

In Eq. (5a), $K_{\mathrm{PS}}$ is given by Li-Ma-Yang model (Li et al., 2015),

$\log K_{\mathrm{PS}}=\log K_{\mathrm{P}-\mathrm{HB}}+\log \alpha$

where the equilibrium term $\log K_{\mathrm{P}-\mathrm{HB}}$ is given by Eq. (3b), and the nonequilibrium term $\log \alpha$ given by

$\log \alpha=-\log \left(1+2.09 / C \times 10^{-10} f_{\mathrm{OM}} K_{\mathrm{OA}}\right)$

The value for $C$ is suggested to be 5 for city sites and 50 for sites with high wind speed (Li et al., 2015).

The Li-Ma-Yang model implies that there are two threshold values of $\log K_{\mathrm{OA}}, \log K_{\mathrm{OA} 1}(=11.4)$ and $\log K_{\mathrm{OA} 2}(=12.5)$, which divide the range of $\log K_{\mathrm{OA}}$ into three domains: an equilibrium (EQ) domain (log $K_{\mathrm{OA}} \leq \log K_{\mathrm{OA} 1}$ ), a non-equilibrium (NE) domain (log $K_{\mathrm{OA} 1}<\log$ $K_{\mathrm{OA}}<\log K_{\mathrm{OA} 2}$ ), and a maximum partition (MP) domain (log $K_{\mathrm{OA}} \geq$ $\log K_{\mathrm{OA} 2}$ ). For this latter domain, the maximum value of $\log K_{\mathrm{OA}}$ is a constant (-1.53) (Figure A.2).

\section{Results}

\subsection{Concentrations of particles}

For Harbin air samples, concentrations of total suspended particles (TSP) are from 17.4 to $642 \mu \mathrm{g} / \mathrm{m}^{3}$ with a geometric mean (GM) of 109 $\mu \mathrm{g} / \mathrm{m}^{3}$ (Table A.1). The distribution of particle sizes is bimodal with peaks at $0.56-1 \mu \mathrm{m}$ and $3.2-5.6 \mu \mathrm{m}$. The $3.2-5.6 \mu \mathrm{m}$ peak is highest when $T>10^{\circ} \mathrm{C}$, but this shifts when $T<10^{\circ} \mathrm{C}$ and $0.56-1 \mu \mathrm{m}$ becomes highest (Figure A.3). The sum of all particulate size ranges, $\Sigma P M_{\mathrm{i}}$, is found to be less than TSP. As shown in Figure A.4, there is a significant correlation between $\Sigma P M_{\mathrm{i}}$ and TSP $(r=0.98, p<0.01)$, and the GM value of $\Sigma P M_{\mathrm{i}} /$ TSP is $61.9 \%$ ranging from $49.2 \%-81.2 \%$, with more than $72.1 \%$ of the values within the range of $61.9 \% \pm 10 \%$. This result is close to $59.0 \pm 17 \%$ observed over the Lake Michigan and higher than $45.7 \pm 7 \%$ observed at Chicago (Offenberg and Baker, 1999). This ratio may be in whole or in part a result of the different particle-collection mechanisms (efficiencies) for the two samplers.

\subsection{Concentrations and size-distribution of PBDEs}

Concentrations of the eight PBDE congeners $\left(\Sigma_{8} \mathrm{PBDE}\right)$ (particleplus gas- phases) in the Harbin atmosphere are in the range of $6.3-190$ $\mathrm{pg} / \mathrm{m}^{3}$ with a GM value of $57 \mathrm{pg} / \mathrm{m}^{3}$ (see Table A.4). Among these, BDE-209 is the most abundant congener with a range of $4.6-180 \mathrm{pg} /$ $\mathrm{m}^{3}$ and a GM of $46 \mathrm{pg} / \mathrm{m}^{3}$. The concentrations of the other seven PBDE congeners $\left(\Sigma_{7} \mathrm{PBDE}\right)$ (particle- plus gas- phases) range from 1.2 to 31 $\mathrm{pg} / \mathrm{m}^{3}$ with a GM value of $7.3 \mathrm{pg} / \mathrm{m}^{3}$. Compared to PBDEs levels reported for other locations (Table A.5), atmospheric PBDEs in Harbin are slightly reduced in the past decade (Qi et al., 2014), and comparable with urban sites in Kyoto, Japan (Hayakawa et al., 2004), Chicago, USA 
(Hoh and Hites, 2005), Izmir, Turkey (Cetin and Odabasi, 2007) and Greece (Mandalakis et al., 2009) but higher than a background site in Czech Republic (Degrendele et al., 2018) and at the Great Wall station in Antarctica (Wang et al., 2017). In China, Harbin has relatively low PBDEs concentrations compared to industrial cities in South China (Chen et al., 2006; Han et al., 2009; Zhang et al., 2009) and Beijing (Cao et al. 2018a).

For size-segregated particles (Fig. 1) BDE-209 also has the highest concentrations, more than one order of magnitude higher than the remaining seven PBDE congeners in all size-ranges, but highest in sizeranges of $0.56-1 \mu \mathrm{m}$ and 3.2-5.6 $\mu \mathrm{m}$ (both $3.7 \mathrm{pg} / \mathrm{m}^{3}$ ). Except for BDE17 and -209 , the concentrations for the other six PBDEs congeners show a unimodal distribution with peaks at the size-range of $0.56-1 \mu \mathrm{m}$. Data collected for Guangzhou, China, shows that the size-distribution of $\Sigma_{5}$ PBDE (BDE-47, -99, -183, -207 and -209) also has the major peak at a size-range of $0.56-1 \mu \mathrm{m}$ (Zhang et al., 2012). This distribution is possibly due to the large abundance of fine particles and the lowest dry deposition velocity for atmospheric particles around $1 \mu \mathrm{m}$ (Zhang et al., 2001).

The GM concentrations of PBDEs for all 11 size-ranges of particles $\left(\Sigma C_{\mathrm{Pi}_{\mathrm{i}}}\right.$ ) were calculated and compared with those in TSP (Figure A.5). The $\Sigma C_{\mathrm{Pi}}$ for BDE-209 and for the remaining seven PBDE congeners are $35 \mathrm{pg} / \mathrm{m}^{3}$ and $3.6 \mathrm{pg} / \mathrm{m}^{3}$, respectively, which accounts for approximate $90.4 \%$ of the PBDEs in TSP ( $39 \mathrm{pg} / \mathrm{m}^{3}$ and $4.0 \mathrm{pg} / \mathrm{m}^{3}$, respectively). Our results are close to the mean, $90.3 \%$, for PAHs captured by the MOUDI over the Lake Michigan and at an urban site in Chicago, USA (Offenberg and Baker, 1999), but higher than the $\sim 70.0 \%$ for PBDEs captured by the MOUDI in the atmosphere of Guangzhou, China (Zhang et al., 2012). The lower amounts of PBDEs captured by the MOUDI compared to the medium-volume sampler is not unexpected, since the former collected only about $61.2 \%$ mass weight of particles compared with the latter.

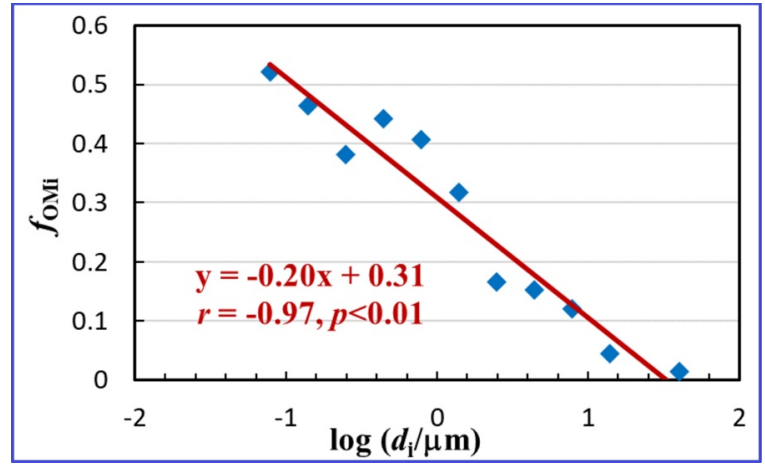

Fig. 2. Variation of the value of $f_{\mathrm{OMi}}$ as a function of logarithm of mean values of particle sizes for each size-range $\left(\log d_{i}\right)$.

\subsection{Organic matter}

The fractions of organic matter, measured in each of the 11 sizeranges $\left(f_{\text {OMi }}\right)$ (Table A.6), had a strong linear relationship with particle size $(r=-0.97, p<0.01)\left(f_{\mathrm{OMi}}=-0.20 \log d_{\mathrm{i}}+0.31\right)$ (Fig. 2). The highest organic matter fraction is associated with the finest particles $(52.1 \%$ in $0.056-0.1 \mu \mathrm{m})$ and decreases as particle size increases to reach the lowest value (1.5\%) in particles larger than $18 \mu \mathrm{m}$. Similar results have been found by other groups in Guangzhou (China) (Yu and Yu, 2009, 2012), Seoul (Korea) (Hwang et al., 2008), Southern California (USA) (Kleeman et al., 1999), in urban Chicago and over Lake Michigan (USA) (Offenberg and Baker, 2000), and in Sapporo (Japan) (Agarwal et al., 2010). We also found good correlations between our $f_{\text {OMi }}$ data and data collected in Seoul $(r=0.84)$, in urban Chicago $(r=$ 0.66 ), and over Lake Michigan ( $r=0.67$ ) (Figure A.6).

The concentrations of $\Sigma_{8}$ PBDEs in the size-segregated particles also show a significant linear relationship with their corresponding $f_{\text {OMi }}(r=$ 0.62, $p<0.05$ ) (Fig. 3). All individual congeners likewise show

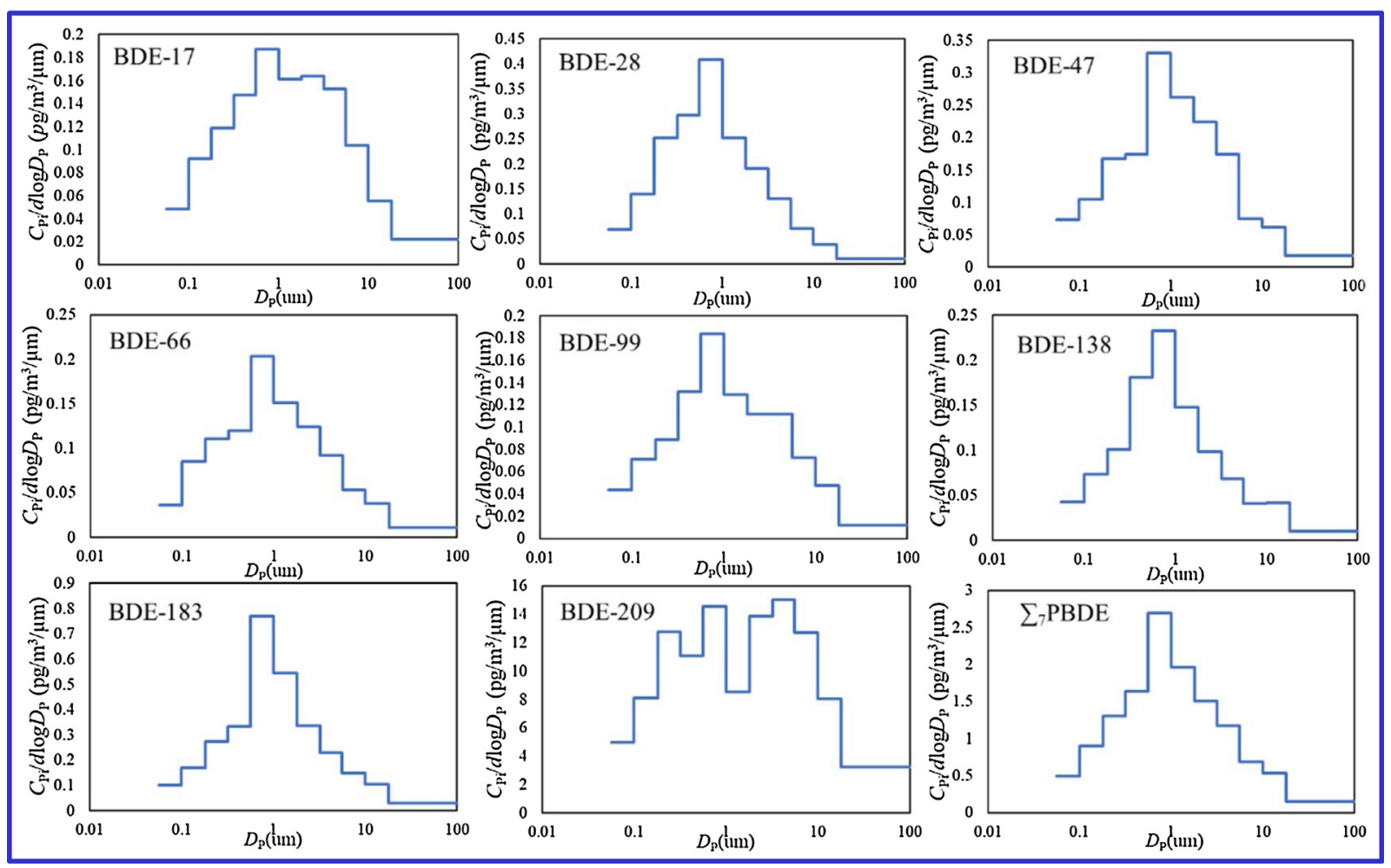

Fig. 1. Concentrations and size-distributions of the eight PBDE congeners (BDE-17, -28, -47, -66, -99, -138, -183, and BDE-209) in the Harbin atmosphere. Note much higher scale for BDE-209. 


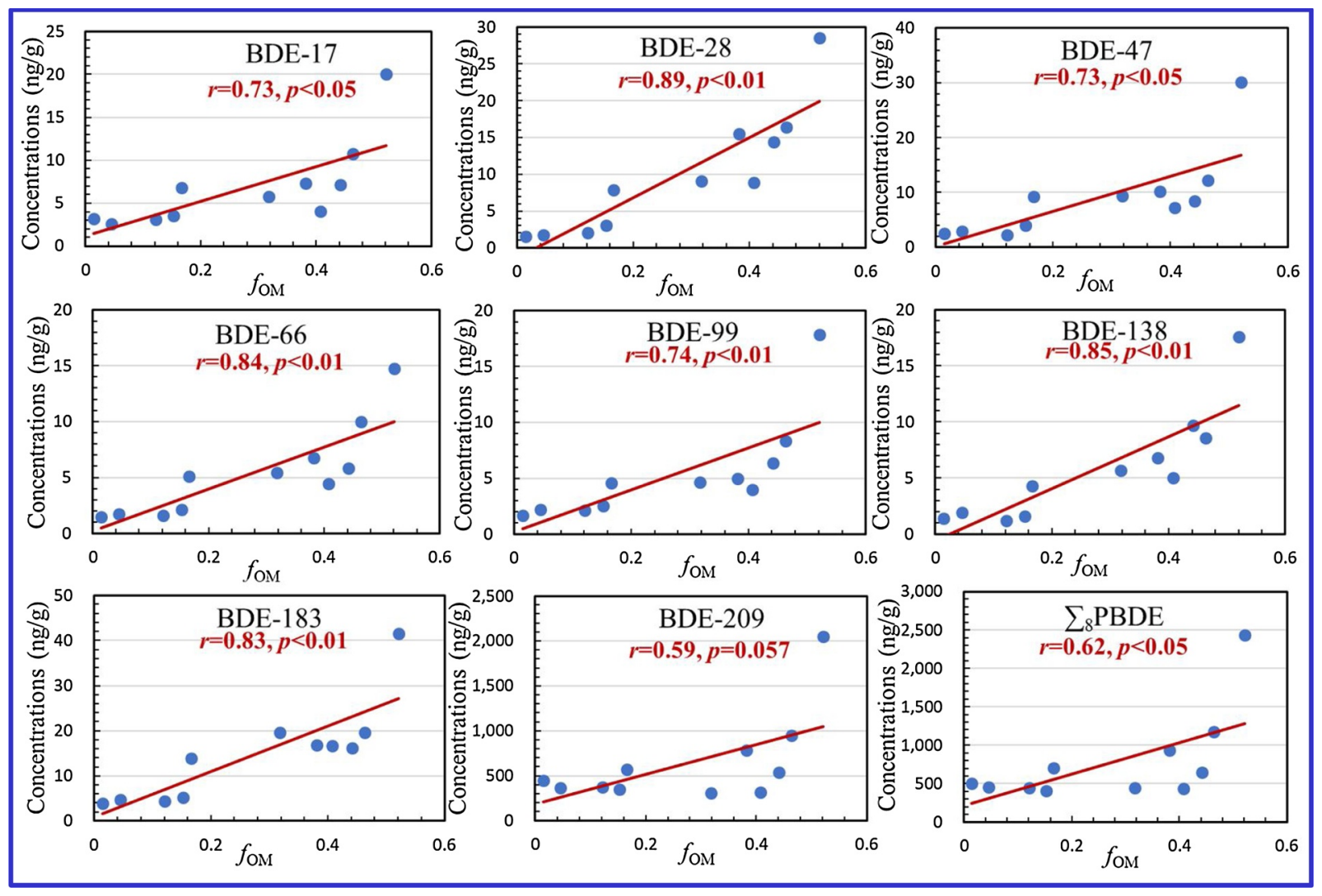

Fig. 3. Variations of mass concentrations of PBDEs congeners as functions of $f_{\mathrm{OMi}}$ -

significant linear correlations with their corresponding $f_{\mathrm{OMi}}(0.73 \leq r$ $\leq$ 0.89, $p<0.05)$ with the exception of BDE-209 $(r=0.59, p=$ $0.057)$. This is not surprising since organic matter provides the absorbent that sequesters SVOCs onto the particles (Harner and Bidleman, 1998; Yu and Yu, 2012). To our knowledge, the data presented here provide the first opportunity to determine the relationship between SVOCs mass concentrations and organic matter contents in size-segregated airborne-particles.

Furthermore, we find a significant linear relationship between log $R_{\mathrm{CPi}} / R_{\mathrm{PMi}}$ (Eq. (5b)) and $\log f_{\mathrm{OMi}}$ expressed as $\log \left(R_{\mathrm{CPi}} / R_{\mathrm{PMi}}\right)=0.52$ $\log f_{\mathrm{OMi}}+0.56(r=0.80, p<0.01$ (Fig. 4)). Thus Eq. (5a) may be reformulated as

$\log K_{\mathrm{Pi}}=\log K_{\mathrm{PS}}+\Delta \log K_{\mathrm{POMi}}$

where $\Delta \log K_{\mathrm{POMi}}$ is the deviation of $\log K_{\mathrm{Pi}}$ from the bulk $\log K_{\mathrm{PS}}$ as a function of $\log f_{\mathrm{OMi}}$, given by

$\Delta \log K_{\mathrm{POMi}}=0.52 \log f_{\mathrm{OMi}}+0.56$.

This equation then provides the means to predict the G/P partitioning behavior between gaseous and size-segregated PBDEs by using $f_{\text {OMi }}$.

\subsection{G/P partitioning behavior of PBDEs}

Following the approach taken by Li et al. (2017), we define an acceptable deviation range (ADR) as the region bounded by a deviation in logarithmic values of \pm 1 . Specifically, a model prediction for $\log K_{\mathrm{P}}$ would be acceptable for data falling within the range $\log K_{\mathrm{P}}-1 \leq \log$ $K_{\mathrm{P}} \leq \log K_{\mathrm{P}}+1$. A comparison of monitoring data (this study) with the modeled G/P partitioning quotients for bulk particles (Figure A.7) shows that the Li-Ma-Yang model provides a good fit as seen Figure A.2. For PBDEs, and considering bulk particles, $90.7 \%$ of the data points across all three domains lie within the ADR for $\log K_{\mathrm{PS}}$ values, compared to $50.9 \%$ of the data points within the ADR for $\log K_{\mathrm{P}-\mathrm{HB}}$ (Table A.7). In MP Domain, 87.8\% of the points lie within the ADR for $\log K_{\mathrm{PS}}$, while only $7.6 \%$ meet this criterion for $\log K_{\mathrm{P}-\mathrm{HB}}$.

For the 11 size-segregated particles, both Eq. (5), based on $R_{\mathrm{CPi}} /$ $R_{\mathrm{PMi}}$, and Eq. (10), based on $f_{\mathrm{OMi}}$, may be used to predict the $\mathrm{G} / \mathrm{P}$ partitioning quotients ( $\log K_{\mathrm{PS}-\mathrm{RRi}}$ and $\log K_{\mathrm{PS}-\mathrm{OMi}}$, respectively) of PBDEs as functions of $\log K_{\mathrm{OA}}$. As shown in Fig. 5, the values of $\log K_{\mathrm{PS} \text { - }}$ RRi and $\log K_{\mathrm{PS}-\mathrm{OMi}}$ are similar. The values of $\log K_{\mathrm{PS}-\mathrm{RR} i}$, represented by red circles are seen as points scattered along the trend curve of $\log K_{\mathrm{PS}}$ given by Eq. (8) for bulk air. All points for the 11 size-ranges show an increasing trend with $\log K_{\mathrm{OA}}$ within the $\mathrm{EQ}$ domain and then flatten out in the MP domain $\left(\log K_{\mathrm{OA}} \geq 12.5\right)$. Eq. (10) (log $\left.K_{\mathrm{PS} \text {-OMi }}\right)$ more concisely predicts the G/P partitioning quotients of PBDEs for size-resolved particles. As shown in Fig. 5 , the $\log K_{\mathrm{PS} \text {-OMi }}$ curves are parallel to that of $\log K_{\mathrm{PS}}$. Like the $\log K_{\mathrm{PS}}$ curve, $\log K_{\mathrm{PS} \text {-OMi }}$ also levels out to a maximum value for all the 11 size-ranges when $\log K_{\mathrm{OA}} \geq 12.5$. The maximum value varies from -1.93 for $18-100 \mu \mathrm{m}$ to -1.11 for

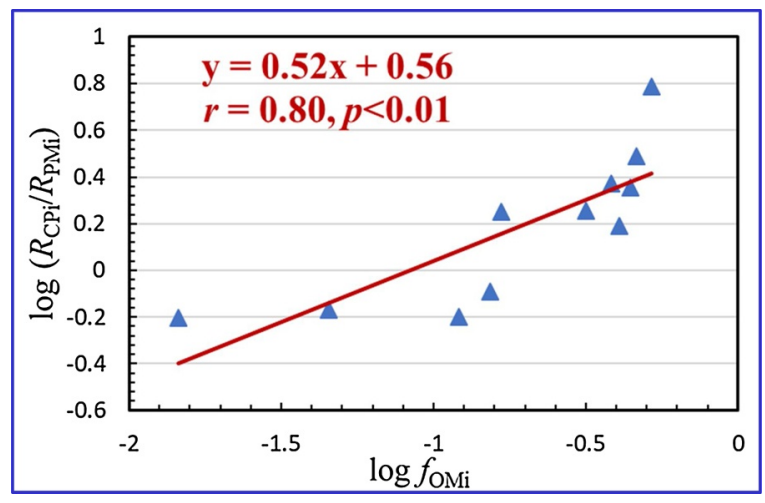

Fig. 4. Linear relationship between $\log \left(R_{\mathrm{CPi}} / R_{\mathrm{PMi}}\right)$ and $\log f_{\mathrm{OMi}}$. 


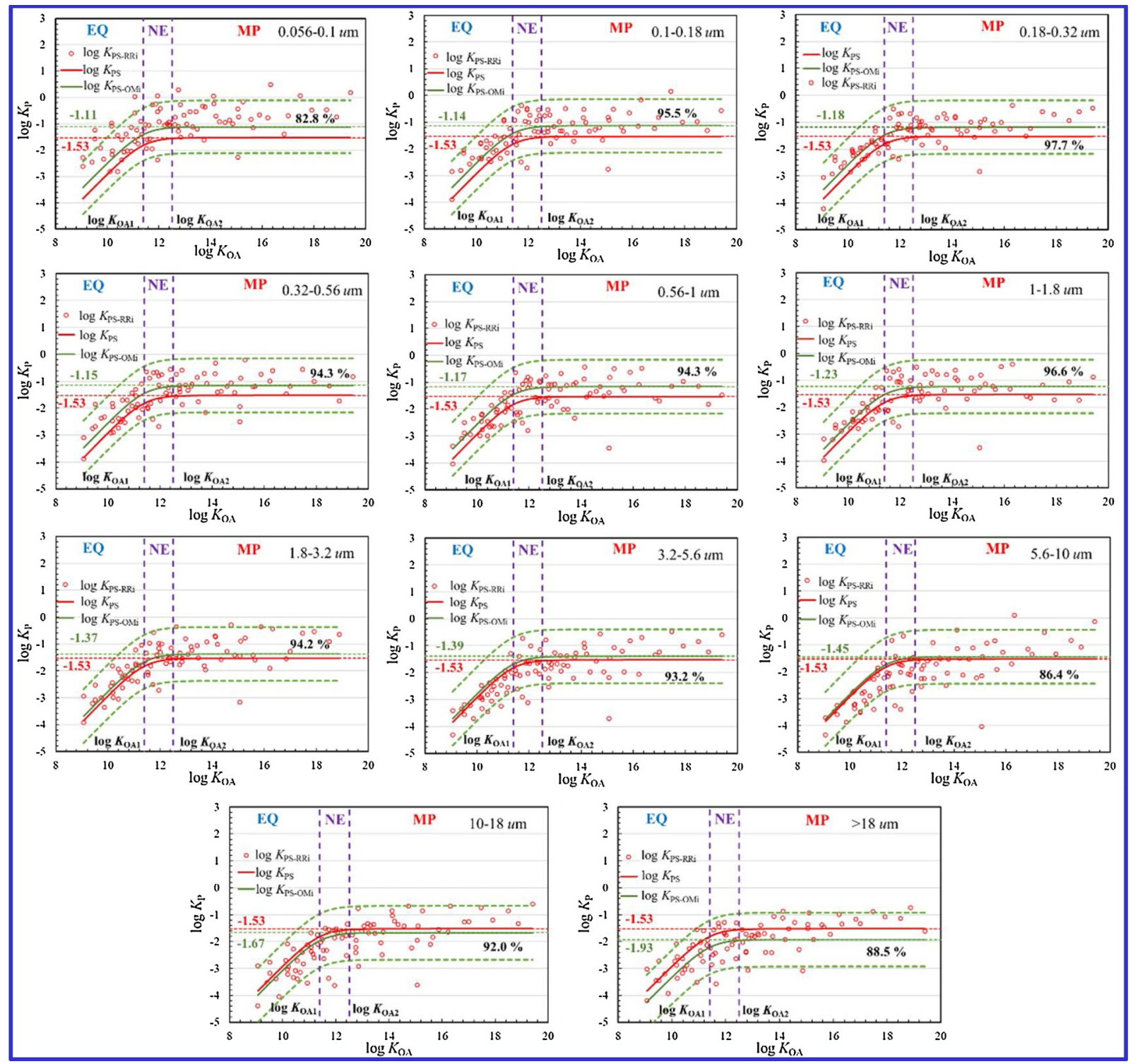

Fig. 5. The prediction of G/P partitioning quotients of PBDEs in 11 size-ranges by Eq. (5) (log $K_{\mathrm{PS}-\mathrm{RRi}}$, red circles) and Eq. (10) (log $K_{\mathrm{PS}-\mathrm{OMi}}$, solid green lines) as functions of $\log K_{\mathrm{OA}}$. The two dashed green lines give the $\pm 1 \log$ unit boundaries for $\log K_{\mathrm{Ps} \text {-omi. }}$. The curves of $\log K_{\mathrm{PS}}$ (the red line) for bulk particles are also included for comparison.

$0.056-0.1 \mu \mathrm{m}$. More importantly, almost all the points of log $K_{\mathrm{PS}-\mathrm{RRi}}$ in each size-range are distributed within the ADR of the corresponding curve for $\log K_{\mathrm{PS}-\mathrm{OMi}}$ (from $82.8 \%$ for the size-range of $0.056-0.1 \mu \mathrm{m}$ to $97.7 \%$ for the size-range of $0.18-0.32 \mu \mathrm{m})$.

In general, the results projected by Eq. (5) and Eq. (10) are proximate, and both equations give the same predicted $\mathrm{G} / \mathrm{P}$ partitioning trend for PBDEs. However, it is more difficult to apply Eq. (5) since the values of $R_{\mathrm{CPi}}$ and $R_{\mathrm{PMi}}$ are difficult to obtain, whereas Eq. (10) needs only the values of $f_{\mathrm{OMi}}$ in the size-resolved particles. Eq. (10) also reveals that absorption is the major mechanism for binding PBDEs onto particles, as indicated by Eq. (8) for bulk particles.

\subsection{Evaluation of Eq. (10) and Eq. (3a) using monitoring data}

As in the case of Eq. (10), Eq. (3a) developed by Lyu et al. (2016) needs only the values of $f_{\mathrm{OMi}}$ in the size-segregated particles, which permits a direct comparison of the two equations. Here we evaluate Eq. (10) $\left(\log K_{\mathrm{PS}-\mathrm{OMi}}\right)$ and Eq. (3a) (log $\left.K_{\mathrm{P}-\mathrm{HBi}}\right)$ by setting their projected results against monitoring data collected in Harbin air and elsewhere. The values of $f_{\text {OMi }}$ used in this evaluation are listed in Table A.6, and the detail percentages of monitoring data falling in the ADRs of Eq. (10) and Eq. (3a) are listed in Table A.8.

For particles distributed in 11 size-ranges in Harbin (Figure A.8), the percentages of monitoring data $\left(\log K_{\mathrm{Pmi}}\right)$ falling within the ADR of Eq. (10) (log $\left.K_{\mathrm{PS}-\mathrm{OMi}}\right)$ predictions are from $71.3 \%$ to $94.3 \%$, compared to $42.5 \%-51.7 \%$ for the Eq. (3a) $\left(\log K_{\mathrm{P}-\mathrm{HBi}}\right)$ predictions. The greatest difference may be seen in the MP Domain, in which the percentages are, respectively, $72.5 \%-90.0 \%$ and $2.5 \%-15.0 \%$ (see Table A.8 for the data in each size-range). The mean values for all monitoring data in the MP Domain compared with the predicted data from the two equations in 11 size-ranges (Fig. 6) shows that Eq. (10) provides an acceptable fit for all the 11 size-ranges while Eq. (3a) fails completely.

Su et al. (2018) measured air concentrations, size-segregated particle concentrations and G/P partition quotients for nine PBDE congeners (BDE-17, -28, -47, -85, -99, -100, -153, -154 and BDE-183) in Shanghai, China. For that study, particles were divided into six sizeranges ( $<0.4 \mu \mathrm{m}, 0.4-1.1 \mu \mathrm{m}, 1.1-2.1 \mu \mathrm{m}, 2.1-5.8 \mu \mathrm{m}, 5.8-9 \mu \mathrm{m}$ and $>9 \mu \mathrm{m}$ ). Based on the $f_{\text {OMi }}$ measured in the present study for the 11 size-ranges, we estimated the values of $f_{\mathrm{OMi}}$ for the six size-ranges for the Shanghai study, and the resultant Clausius-Clapeyron coefficients, 


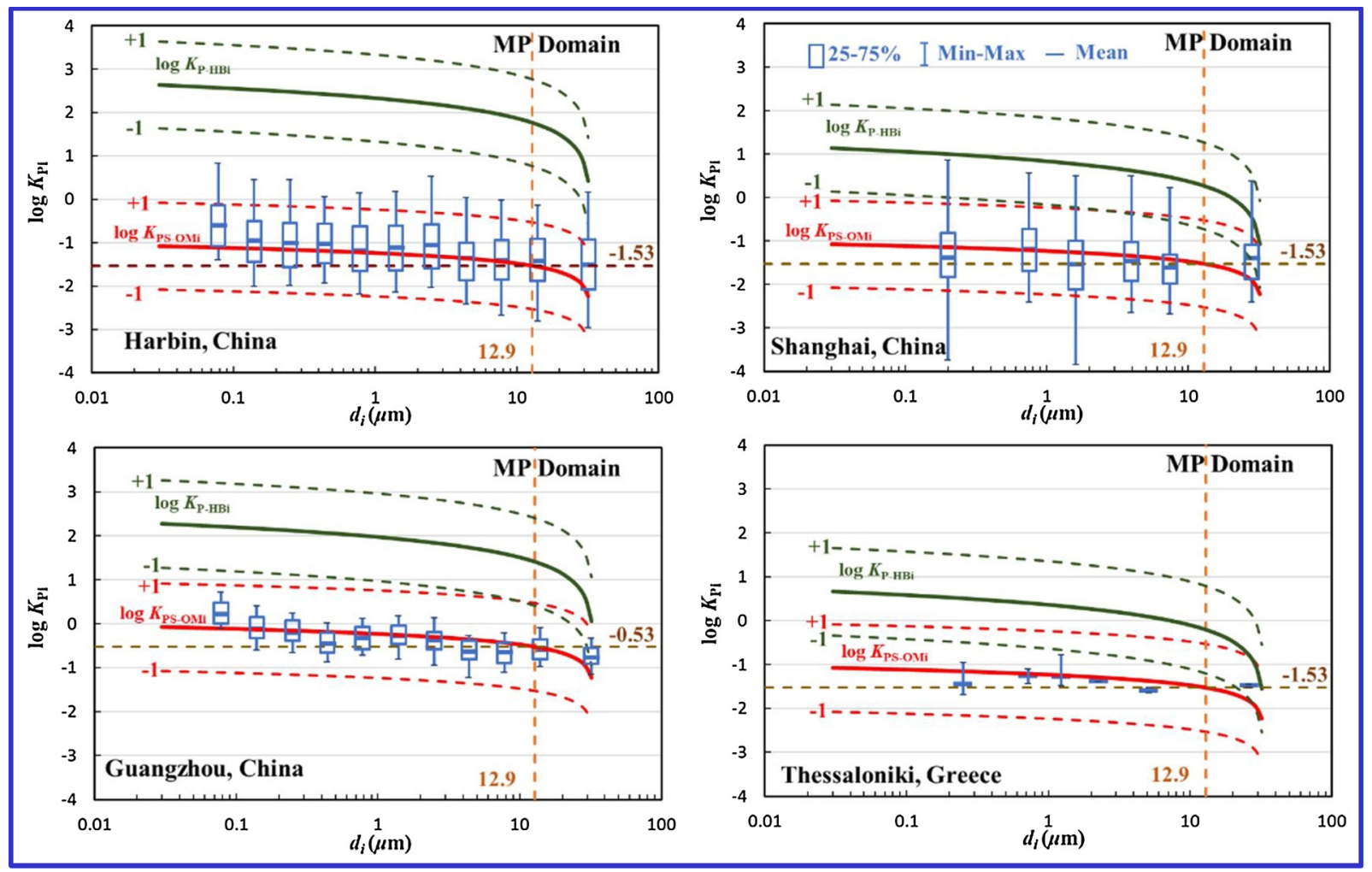

Fig. 6. The predicted results $\log K_{\mathrm{PS}-\mathrm{OMi}}$ by Eq. (10) (red line) and $\log K_{\mathrm{P}-\mathrm{HBi}}$ by Eq. (3a) (dark green line) along with the the monitoring data in the MP Domain in each size-range as functions of particle size $\left(d_{\mathrm{i}}\right)$ in Harbin (this study), Shanghai (Su et al., 2018), and Guangzhou (Zhang et al., 2012), China and Thessaloniki, Greece (Besis et al., 2015). In Eq. (3a), $\log K_{\mathrm{OA}}$ was the mean value for corresponding monitoring data with $\log K_{\mathrm{OA}}>12.5$. The 2 dashed red lines give the \pm 1 log unit boundaries for $\log K_{\mathrm{PS} \text {-OMi, }}$, and the 2 dashed dark green lines give the $\pm 1 \log$ unit boundaries for $\log K_{\mathrm{P} \text {-HBi. }}$. Bar and whisker plots are presented for the monitoring data in Harbin, Shanghai, and Guangzhou, whereas the mean, maximum, and minimum are given for the monitoring data in Thessaloniki.

$A_{\mathrm{O}}$ and $B_{\mathrm{O}}$, for the nine PBDE congeners (Table A.3) were used to calculate the values of $\log K_{\mathrm{OA}}$. Figure A.9

presents the Shanghai monitoring data together with the predictions of Eqs. (10) and (3a) for each size-range as functions of $\log K_{\mathrm{OA}}$. As the case in Harbin, Eq. (10) (log $\left.K_{\mathrm{PS}-\mathrm{OMi}}\right)$ performs far better than Eq. (3a) $\left(\log K_{\mathrm{P}-\mathrm{HBi}}\right)$ in its prediction. This is especially true in the MP domain, in which $71.4 \%-90.9 \%$ of the monitoring data lie within the ADR of Eq. (10) compared to $2.3 \%-40.0 \%$ for Eq. (3a). As clearly indicated in Fig. 6, the mean values for monitoring data in the MP Domain in all six size ranges are within the ADR of Eq. (10) and outside that of Eq. (3a).

Zhang et al., 2012 collected air and size-resolved particle samples for five PBDE congeners (BDE-47, BDE-99, BDE-183, BDE-207 and BDE209) at the $50 \mathrm{~m}$ and $150 \mathrm{~m}$ heights in Guangzhou, China in August and December 2010, using the same type of MOUDI sampler with the same 11 size-stages as used in the Harbin study. TSP, $P M_{\mathrm{i}}$, and $f_{\mathrm{OMi}}$ are not given by the authors, thus we assume $T S P=100 \mu \mathrm{g} / \mathrm{m}^{3}$ and use the values of $R_{\mathrm{PMi}}$ and $f_{\mathrm{OMi}}$ measured in the Harbin study for this evaluation. In Eq. (9), $C=50$ is used in consideration of the large wind-speed at the sampling site. For the Guangzhou data (Figure A.10), all of the points lie within the ADR for Eq. (10), indicating that $\log K_{\mathrm{PS}-\mathrm{OMi}}$ is a good prediction for particles with the sizes of $0.1-10 \mu \mathrm{m}$ (containing eight size-ranges), whereas only $42.5 \%-60.0 \%$ of the data lie within the ADR of the Eq. (3a) prediction. In the MP domain, all of the monitoring data in all 11 size-ranges fall into the ADR of $\log K_{\mathrm{PS} \text {-OMi }}$, but only $18.2 \%-40.9 \%$ for $\log K_{\mathrm{P}-\mathrm{HBi}}$. Similar to the case of Harbin data, Eq. (10) can predict the monitoring data in all 11 size-ranges in comparison to only largest size-range ( $>18 \mu \mathrm{m}$ ) by Eq. (3a) (Fig. 6).

Besis et al. (2015) reported values for $C_{\mathrm{Pi}}$ and $P M_{\mathrm{i}}$ for nine PBDEs congeners (BDE-17, BDE-28, BDE-47, BDE-66, BDE-99, BDE-100, BDE153, BDE-154 and BDE-183) for particles within six size-ranges $(<0.49$ $\mu \mathrm{m}, 0.49-0.95 \mu \mathrm{m}, 0.95-1.5 \mu \mathrm{m}, 1.5-3 \mu \mathrm{m}, 3-7.2 \mu \mathrm{m}$ and $>7.2 \mu \mathrm{m})$ for Thessaloniki, northern Greece. The samples were collected at an urban traffic site and an urban background site with the temperature ranging from $9.6{ }^{\circ} \mathrm{C}$ to $26.3^{\circ} \mathrm{C}$. The gaseous concentrations of PBDEs, which were not measured in their study, were estimated using the LiMa-Yang model. We calculated the values of $\log K_{\mathrm{PS}-\mathrm{OMi}}$ and $\log K_{\mathrm{P}-\mathrm{HBi}}$ as functions of $\log K_{\mathrm{OA}}$ and found that $\log K_{\mathrm{PS} \text {-OMi }}$ predicted $\log K_{\mathrm{Pmi}}$ better than $\log K_{\mathrm{P}-\mathrm{HBi}}$ (Figure A.11). In all three domains, $100 \%$ of the $\log K_{\mathrm{Pmi}}$ for all the six size-ranges lay within the ADR of Eq. (10), whereas in MP Domain, the percentages of the $\log K_{\mathrm{Pmi}}$ falling within the ADR of the Eq. (3a) prediction were zero in five of the six sizeranges, as clearly shown in Fig. 6.

\section{Discussions}

\subsection{Important parameters}

If samples only of size-segregated particles are collected during monitoring, $\Sigma C_{\mathrm{Pi}}$ and $\Sigma P M_{\mathrm{i}}$ are usually used to estimate of $C_{\mathrm{P}}$ and TSP, respectively. This, however, produces a bias since $\Sigma C_{\mathrm{Pi}}$ and $\Sigma P M_{\mathrm{i}}$ are often less than $C_{\mathrm{P}}$ and TSP, respectively, as evidenced by ours and other group's monitoring data (Offenberg and Baker, 1999; Zhang et al., 2012). By definition, $R_{\mathrm{CPi}}$ and $R_{\mathrm{PMi}}$ in Eqs. (6) and (7)should be equivalent to the concentrations of chemicals and particles in size-range $i$ divided by the corresponding value in bulk air $\left(C_{\mathrm{P}}\right.$ and TSP), and not necessarily the total value within a set of size-ranges $\left(\Sigma C_{\mathrm{Pi}}\right.$ and $\left.\Sigma P M_{\mathrm{i}}\right)$. If $\Sigma C_{\mathrm{Pi}}$ and $\Sigma P M_{\mathrm{i}}$ are as substituted for $\mathrm{C}_{\mathrm{P}}$ and $T S P$, the values of $\log K_{\mathrm{Pi}}$ (Eq. (5)) will be under-estimated by a factor of 0.17 for each size-range particle (seeing in Figure A.12), which would be acceptable under our ADR. Since Eq. (10) is based on $f_{\mathrm{OMi}}$, the use of $\Sigma C_{\mathrm{Pi}}$ and $\Sigma P M_{\mathrm{i}}$ will not affect the values of $\log K_{\mathrm{Pi}}$ predicted from Eq. (10), showing another advantage of this equation in comparison to Eq. (5). 
The parameter $f_{\mathrm{OMi}}$ is critical for prediction of $\log K_{\mathrm{PS}-\mathrm{OMi}}$ through the use of Eq. (10). Given that $f_{\mathrm{OM}}=M_{\mathrm{OM}} / T S P$, the parameter $f_{\mathrm{OMi}}$ is defined as $M_{\mathrm{OMi}} / P M_{\mathrm{i}}$, where $M_{\mathrm{OM}}$ and $M_{\mathrm{OMi}}$ are the OM concentrations $\left(\mu \mathrm{g} / \mathrm{m}^{3}\right.$ air) in the TSP and particles at size-range $i$, respectively. Thus, $f_{\mathrm{OM}} \neq \Sigma f_{\mathrm{OMi}}$, since $f_{\mathrm{OM}}$ is not uniformly distributed among entire particle size-ranges (Fig. 2). Therefore, it is a straight forward conclusion that equation $f_{\mathrm{OM}}=\int f_{\mathrm{OMi}}\left(d_{i}\right)$ dlog $d_{\mathrm{i}}$ (Venkataraman et al., 1999) is not correct either. Rather, the correct expression should be $f_{\mathrm{OM}}=M_{\mathrm{OM}} /$ $T S P=\Sigma\left(f_{\text {OMi }} \times P M_{\mathrm{i}}\right) / T S P$, or $f_{\text {OM }}=\int\left(f_{\text {OMi }}\left(d_{i}\right) \times P M_{\mathrm{i}}\left(d_{i}\right)\right) \mathrm{d} d_{i} / T S P$.

\subsection{The relationship between $K_{P}$ and $K_{P i}$}

As depicted in Eqs. (3a), (5) and (10), all equations of $K_{\mathrm{Pi}}$ relate to the bulk $K_{\mathrm{P}}$, and follow the same trends with deviations $\left(\Delta \log K_{\mathrm{PHBi}}\right.$, $\Delta \log K_{\mathrm{PRi}}$ and $\Delta \log K_{\mathrm{POMi}}$, respectively) from the bulk values (Figure A.13) with $K_{\mathrm{Pi}}$ equal to $K_{\mathrm{P}}$ when $\log \left(R_{\mathrm{CPi}} / R_{\mathrm{PMi}}\right)=0\left(R_{\mathrm{CPi}}=R_{\mathrm{PMi}}\right)$ for $\log K_{\mathrm{PS}-\mathrm{RRi}}, \log f_{\mathrm{OMi}}=-1\left(f_{\mathrm{OMi}}=0.1\right)$ for $\log K_{\mathrm{P}-\mathrm{HBi}}$, and $\log f_{\mathrm{OMi}}=$ $-1.07\left(f_{\mathrm{OMi}}=0.084\right)$ for $\log K_{\mathrm{PS}-\mathrm{OMi}}$.

$K_{\mathrm{P}}$ and $K_{\mathrm{Pi}}$ are, respectively, defined by Eqs. (1) and (2). It is important to note that $K_{\mathrm{P}} \neq \Sigma K_{\mathrm{Pi}}$. In the MP domain, for example, $\log K_{\mathrm{PS}-}$ OMi ranged from -1.93 to -1.11 in the 11 size-ranges, whereas $\Sigma K_{\mathrm{Pi}}=$ 0.57 , which is much higher than that of the bulk particles by more than an order of magnitude $\left(K_{\mathrm{PS}}=0.03, \log K_{\mathrm{PS}}=-1.53\right)$. If $\Sigma C_{\mathrm{Pi}}$ and $\Sigma P M_{\mathrm{i}}$ are to be used as $C_{\mathrm{P}}$ and $T S P$, then $K_{\mathrm{P}}=\left(C_{\mathrm{P}} / T S P\right) / C_{\mathrm{G}}=\left(\Sigma C_{\mathrm{Pi}} / \Sigma P M_{\mathrm{i}}\right)$ $/ C_{\mathrm{G}}$. Some researchers have used the integral form of the equation to express the relationship between $K_{\mathrm{P}}$ and $K_{\mathrm{Pi}}$, given as $K_{\mathrm{P}}=\int K_{\mathrm{Pi}}\left(d_{i}\right)$ dlogd $d_{i}$ (Offenberg and Baker, 2002; Venkataraman et al., 1999), which is not correct.

\subsection{Comments on Eq. (10)}

All of the evaluations presented in Section 3.5 suggest that the equation for size-resolved G/P partitioning quotients of PBDEs deduced in this study under steady state $\left(\log K_{\mathrm{PS}-\mathrm{OMi}}\right)(\mathrm{Eq}$. (10)) is superior to other available equations in prediction of the G/P partitioning behavior for size resolved particles for PBDEs. This is especially true in the MP domain where $\log K_{\mathrm{OA}} \geq 12.5$. The equation is applicable to size-resolved particles in Harbin, Shanghai and Guangzhou in China, and Thessaloniki in Greece. We infer therefore, that this equation could be used worldwide. Eq. (10) is based on an assumption of steady-state dynamics. Since the steady-state Equation (Eq. (8)) can be applied to other chemicals, as described in the Introduction, Eq. (10) should also be capable of predicting $\mathrm{G} / \mathrm{P}$ behavior for size-segregated particles for these chemicals, such as alternative halogenated flame retardants, nonPBDE brominated flame retardants, PCDD/Fs, and OCPs.

Uncertainties that occur in the bulk steady-state equation would, likewise, apply to Eq. (10). According to Eq. (10), an important new source of uncertainty for the G/P partitioning for size-resolved particles arises from the variation of $f_{\mathrm{OMi}}$. According to the predictions, however, the effect on $\log K_{\mathrm{Pi}}$ caused by variation of $f_{\mathrm{OMi}}$ is not significant. Particles in the size range $0.056-0.1 \mu \mathrm{m}$, for example, have highest $\mathrm{OM}$ contents $(52.1 \%)$ in our monitoring data, and thus have the largest deviation, $\Delta \log K_{\mathrm{POMi}}$, from bulk values. This deviation is approximately 0.46 , less than half order of magnitude. In another words, values of $\log K_{\mathrm{P}}$ for the size-resolved particles would still fall into the ADR for bulk particles.

Eq. (10) could be used for any data set from impactors that produce size-range partitioning of particles as long as the organic matter contents in each size-range are also measured, as discussed in Section 3.5. In practice, the values of $f_{\mathrm{OMi}}$ are not easy to measure for monitoring data. In this case, we suggest using the values of $f_{\mathrm{OMi}}$ for different stages given by Table A.6.

The success of Eq. (10) infers that, as in the bulk particles, PBDEs in the atmosphere are in the steady state but not necessary equilibrium between gas and size-segregated particles, and organic matter content in each size stage is the leading factor controlling the deviation of particles in this stage from bulk particles in terms of absorption-dominant partition quotients of PBDEs.

\subsection{Application and prospect on healthy exposure}

Gaseous and particulate SVOCs present health risks to humans by entering the body through inhalation or skin (Geiser et al., 2005; Gravel et al., 2019; La Guardia and Hale, 2015; Wang et al., 2019). In comparison to the gaseous phase, particulate SVOCs exhibit a complicated distribution in the atmosphere reflecting variable particle size-distributions. This makes it difficult to evaluate the particulate contribution to exposure dose into the human body (Cao et al., 2018a, 2019; Jin et al. 2017a; Lao et al., 2018). By combining a size-resolved G/P partitioning equation and a health exposure model, a realistic particulate PBDEs exposure dose can be predicted, even where only gaseous PBDEs data are available.

Taking the inhalation exposure of PBDEs as an example. Eq. (3a) and Eq. (10) are combined, separately, with International Commission on Radiological Protection (ICRP) model (Hinds, 1999), forming log $K_{\mathrm{P}-}$ $\mathrm{HBi}^{-}$ICRP for the former and $\log K_{\mathrm{PS}-\mathrm{OMi}}$-ICRP for the latter, to predict the exposure doses of particulate PBDEs (details seeing Section A.4), with measured concentrations of gaseous PBDEs and size-segregated particles. The predicted inhalation exposure doses of particulate PBDEs for Harbin, Shanghai and Guangzhou of China are plotted in Fig. 7, Figure A.14, and Figure A.15, respectively (the monitoring $C_{\mathrm{Pi}}$ and predicted $C_{\mathrm{Pi}}$ seeing in Table A.9). The predicted inhalation exposure doses by $\log K_{\mathrm{PS}-\mathrm{OMi}} \mathrm{ICRP}$ are much close to the exposure doses from monitoring data, in Harbin and Guangzhou of China, and within 1 magnitude accuracy of the monitoring data collected in Shanghai of China. Meanwhile, the $\log K_{\mathrm{P}-\mathrm{HBi}}$-ICRP are highly over-estimated the inhalation exposure of particulate PBDEs for these three cities.

\section{Conclusion}

The Eq. (10) derived in this study is convenient, and more accurate to predict the $K_{\mathrm{Pi}}$ of PBDEs than the previous equation. The equation reveals that the organic-matter-determining absorption process dominates the partitioning behavior of atmospheric PBDEs between their gaseous phase and size-segregated particles. It turns out that Eq. (10) is a reliable tool to predict the G/P partitioning quotients of PBDEs in gas phase and size segregated particles, and further helps researchers to obtain the healthy exposure dose from atmospheric PBDEs.

\section{CRediT authorship contribution statement}

Peng-Tuan Hu: Conceptualization, Formal analysis, Methodology, Visualization, Data curation, Writing - original draft. Peng-Hao Su:

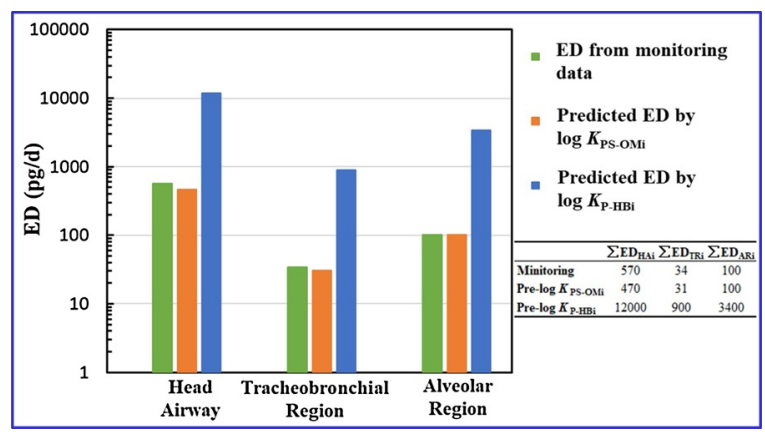

Fig. 7. The inhalation exposure dose (ED) of particulate PBDEs to three regions of human respiratory tract. The green column is ED calculated by the ICRP model directly, with monitoring particulate PBDEs concentrations in Harbin, China; the orange and blue column are the ED calculated by $\log K_{\mathrm{PS}-\mathrm{OMi}}$-ICRP and $\log K_{\mathrm{P}-\mathrm{HBi}}$-ICRP respectively, with the mean concentrations of gaseous $\Sigma_{8}$ PBDEs and corresponding $P M_{\mathrm{i}}$ in Harbin, China. 
Data curation, Writing - review \& editing. Wan-Li Ma: Resources, Writing - review \& editing. Zi-Feng Zhang: Resources. Li-Yan Liu: Resources. Wei-Wei Song: Resources. Li-Na Qiao: Investigation. Chong-Guo Tian: Resources. Robie W. Macdonald: Validation, Writing - review \& editing. Anatoly Nikolaev: Writing - review \& editing. Zhi-Guo Cao: Writing - review \& editing. Yi-Fan Li: Conceptualization, Supervision, Funding acquisition, Writing - review \& editing.

\section{Declaration of Competing Interest}

The authors declare that they have no known competing financial interests or personal relationships that could have appeared to influence the work reported in this paper.

\section{Acknowledgements}

This work was supported by the National Natural Science Foundation of China (No. 21577030), Polar Academy, Harbin Institute of Technology (No. PA-HIT-201901), and State Key Laboratory of Urban Water Resource and Environment (Harbin Institute of Technology) (No. 2019DX04).

\section{Appendix A. Supplementary data}

Supplementary material related to this article can be found, in the online version, at doi:https://doi.org/10.1016/j.jhazmat.2020.123245.

\section{References}

Agarwal, S., Aggarwal, S.G., Okuzawa, K., Kawamura, K., 2010. Size distributions of dicarboxylic acids, ketoacids, alpha-dicarbonyls, sugars, WSOC, OC, EC and inorganic ions in atmospheric particles over Northern Japan: implication for long-range transport of Siberian biomass burning and East Asian polluted aerosols. Atmos. Chem. Phys. 10, 5839-5858. https://doi.org/10.5194/acp-10-5839-2010.

Besis, A., Botsaropoulou, E., Voutsa, D., Samara, C., 2015. Particle-size distribution of polybrominated diphenyl ethers (PBDEs) in the urban agglomeration of Thessaloniki, northern Greece. Atmos. Environ. 104, 176-185. https://doi.org/10.1016/j. atmosenv. 2015.01.019.

Besis, A., Lammel, G., Kukucka, P., Samara, C., Sofuoglu, A., Dumanoglu, Y., Eleftheriadis, K., Kouvarakis, G., Sofuoglu, S.C., Vassilatou, V., Voutsa, D., 2017. Polybrominated diphenyl ethers (PBDEs) in background air around the Aegean: implications for phase partitioning and size distribution. Environ. Sci. Pollut. Res. 24 28102-28120. https://doi.org/10.1007/s11356-017-0285-7.

Bidleman, T.F., 1988. Wet and dry deposition of organic compowzds are controlled by their vapor-particle partitioning. Environ. Sci. Technol. 22, 361-367. https://doi. org/10.1021/es00169a002.

Cao, R., Zhang, H., Zhao, L., Zhang, Y., Geng, N., Teng, M., Zou, L., Gao, Y., Ni, Y., Fu, Q., Chen, J., 2018a. Hazy weather-induced variation in environmental behavior of PCDD/Fs and PBDEs in winter atmosphere of a north China megacity. Environ. Sci. Technol. 52, 8173-8182. https://doi.org/10.1021/acs.est.8b02148.

Cao, Z., Zhao, L.C., Meng, X., Liu, X., Wu, P., Fan, X., Wang, S., Jie, J., Miao, Z., Xu, X., Shen, M., Bu, Q., 2018b. Amplification effect of haze on human exposure to halogenated flame retardants in atmospheric particulate matter and the corresponding mechanism. J. Hazard. Mater. 359, 491-499. https://doi.org/10.1016/j.jhazmat. 2018.07.109.

Cao, Z., Zhao, L.C., Zhang, Y., Ren, M., Zhang, Y., Liu, X., Jie, J., Wang, Z., Li, C., Shen, M., Bu, Q., 2019. Influence of air pollution on inhalation and dermal exposure of human to organophosphate flame retardants: a case study during a prolonged haze episode. Environ. Sci. Technol. 53, 3880-3887. https://doi.org/10.1021/acs.est. $8 \mathrm{~b} 07053$.

Cetin, B., Odabasi, M., 2007. Particle-phase dry deposition and air-soil gas-exchange of polybrominated diphenyl ethers (PBDEs) in Izmir. Turkey. Environ. Sci. Technol. 41, 4986-4992. https://doi.org/10.1021/es070187v.

Chen, L.G., Mai, B.X., Bi, X.H., Chen, S.J., Wang, X.M., Ran, Y., Luo, X.J., Sheng, G.Y., Fu, J.M., Zeng, E.Y., 2006. Concentration levels, compositional profiles, and gas-particle partitioning of polybrominated diphenyl ethers in the atmosphere of an urban city in South China. Environ. Sci. Technol. 40, 1190-1196. https://doi.org/10.1021/ es052123v.

Chen, M., Jiang, J., Gan, Z., Yan, Y., Ding, S., Su, S., Bao, X., 2019. Grain size distribution and exposure evaluation of organophosphorus and brominated flame retardants in indoor and outdoor dust and $\mathrm{PM}_{10}$ from Chengdu. China. J. Hazard. Mater. 365, 280-288. https://doi.org/10.1016/j.jhazmat.2018.10.082.

Chrysikou, L.P., Gemenetzis, P.G., Samara, C.A., 2009. Wintertime size distribution of polycyclic aromatic hydrocarbons (PAHs), polychlorinated biphenyls (PCBs) and organochlorine pesticides (OCPs) in the urban environment: street-vs rooftop-level measurements. Atmos. Environ. 43, 290-300. https://doi.org/10.1016/j.atmosenv. 2008.09.048.

Covaci, A., Gerecke, A.C., Law, R.J., Voorspoels, S., Kohler, M., Heeb, N.V., Leslie, H., Allchin, C.R., de Boer, J., 2006. Hexabromocyclododecanes (HBCDs) in the environment and humans: a review. Environ. Sci. Technol. 40, 3679-3688. https://doi. org/10.1021/es0602492.

Czub, G., McLachlan, M.S., 2004. Bioaccumulation potential of persistent organic chemicals in humans. Environ. Sci. Technol. 38, 2406-2412. https://doi.org/10.1021/ es034871v.

de la Torre, A., Barbas, B., Sanz, P., Navarro, I., Artinano, B., Martinez, M.A., 2018. Traditional and novel halogenated flame retardants in urban ambient air: gas-particle partitioning, size distribution and health implications. Sci. Total Environ. 630, 154-163. https://doi.org/10.1016/j.scitotenv.2018.02.199.

Degrendele, C., Okonski, K., Melymuk, L., Landlova, L., Kukucka, P., Cupr, P., Klanova, J., 2014. Size specific distribution of the atmospheric particulate PCDD/Fs, dl-PCBs and PAHs on a seasonal scale: Implications for cancer risks from inhalation. Atmos. Environ. 98, 410-416. https://doi.org/10.1016/j.atmosenv.2014.09.001.

Degrendele, C., Wilson, J., Kukučka, P., Klánová, J., Lammel, G., 2018. Are atmospheric PBDE levels declining in central Europe? Examination of the seasonal and semi-longterm variations, gas-particle partitioning and implications for long-range atmospheric transport. Atmos. Chem. Phys. 18, 12877-12890. https://doi.org/10.5194/ acp-18-12877-2018.

Finizio, A., Mackay, D., Bidleman, T.F., Harner, T., 1997. Octanol-air partition coefficient as a predictor of partitioning of semi-volatile organic chemicals to aerosols. Atmos. Environ. 31, 2289-2296. https://doi.org/10.1016/S1352-2310(97)00013-7.

Geiser, M., Rothen-Rutishauser, B., Kapp, N., Schurch, S., Kreyling, W., Schulz, H., Semmler, M., Hof, V.I., Heyder, J., Gehr, P., 2005. Ultrafine particles cross cellular membranes by nonphagocytic mechanisms in lungs and in cultured cells. Environ. Health Perspect. 113, 1555-1560. https://doi.org/10.1289/ehp.8006.

Goetz, C.W., Scheringer, M., Macleod, M., Roth, C.M., Hungerbuehler, K., 2007. Alternative approaches for modeling gas-particle partitioning of semivolatile organic chemicals: model development and comparison. Environ. Sci. Technol. 41, 1272-1278. https://doi.org/10.1021/es060583y.

Gotz, C.W., Scheringer, M., Macleod, M., Wegmann, F., Schenker, U., Hungerbuhler, K., 2008. Dependence of persistence and long-range transport potential on gas-particle partitioning in multimedia models. Environ. Sci. Technol. 42, 3690-3696. https:// doi.org/10.1021/es702619p.

Gravel, S., Lavoue, J., Bakhiyi, B., Diamond, M.L., Jantunen, L.M., Lavoie, J., Roberge, B., Verner, M.-A., Zayed, J., Labreche, F., 2019. Halogenated flame retardants and organophosphate esters in the air of electronic waste recycling facilities: evidence of high concentrations and multiple exposures. Environ. Int. 128, 244-253. https://doi. org/10.1016/j.envint.2019.04.027.

Guo, J., Li, Z., Ranasinghe, P., Rockne, K.J., Sturchio, N.C., Giesy, J.P., Li, A., 2020 Halogenated flame retardants in sediments from the Upper Laurentian Great Lakes: implications to long-range transport and evidence of long-term transformation. J. Hazard. Mater. 384. https://doi.org/10.1016/j.jhazmat.2019.121346.

Gutierrez-Daban, A., Fernandez-Espinosa, A.J., Ternero-Rodriguez, M., FernandezAlvarez, F., 2005. Particle-size distribution of polycyclic aromatic hydrocarbons in urban air in southern Spain. Anal. Bioanal. Chem. 381, 721-736. https://doi.org/10. 1007/s00216-004-2909-2.

Han, W.L., Feng, J.L., Gu, Z.P., Chen, D.H., Wu, M.H., Fu, J.M., 2009. Polybrominated diphenyl ethers in the atmosphere of Taizhou, a major E-Waste dismantling area in China. Bull. Environ. Contam. Toxicol. 83, 783-788. https://doi.org/10.1007/ s00128-009-9855-9.

Harner, T., Bidleman, T.F., 1998. Octanol-air partition coefficient for describing particle/ gas partitioning of aromatic compounds in urban air. Environ. Sci. Technol. 32, 1494-1502. https://doi.org/10.1021/es970890r.

Hayakawa, K., Takatsuki, H., Watanabe, I., Sakai, S., 2004. Polybrominated diphenyl ethers (PBDEs), polybrominated dibenzo-p-dioxins/dibenzofurans (PBDD/Fs) and monobromo-polychlorinated dibenzo-p-dioxins/dibenzofurans (MoBPXDD/Fs) in the atmosphere and bulk deposition in Kyoto, Japan. Chemosphere 57, 343-356. https:// doi.org/10.1016/j.chemosphere.2004.06.038.

Hinds, W.C., 1999. Properties, Behavior, and Measurement of Airborne Particles, second edition. A Wiley-Interscience Publiction, USA ftp://ftp.cdc.gov/pub/Documents/ OEL/02.\%20Kuempel/References/Hinds 1999-Aerosol\%20technology.pdf.

Hoh, E., Hites, R.A., 2005. Brominated flame retardants in the atmosphere of the eastcentral United States. Environ. Sci. Technol. 39, 7794-7802. https://doi.org/10. 1021/es050718k.

Hwang, K.W., Lee, J.H., Jeong, D.Y., Lee, C.H., Bhatnagar, A., Park, J.M., Kim, S.H., 2008 Observation of difference in the size distribution of carbon and major inorganic compounds of atmospheric aerosols after the long-range transport between the selected days of winter and summer. Atmos. Environ. 42, 1057-1063. https://doi.org/ 10.1016/j.atmosenv.2007.11.029.

Jin, R., Liu, G., Jiang, X., Liang, Y., Fiedler, H., Yang, L., Zhu, Q., Xu, Y., Gao, L., Su, G., Xiao, K., Zheng, M., 2017a. Profiles, sources and potential exposures of parent, chlorinated and brominated polycyclic aromatic hydrocarbons in haze associated atmosphere. Sci. Total Environ. 593-594, 390-398. https://doi.org/10.1016/j. scitotenv.2017.03.134.

Jin, R., Zheng, M., Yang, H., Yang, L., Wu, X., Xu, Y., Liu, G., 2017b. Gas-particle phase partitioning and particle size distribution of chlorinated and brominated polycyclic aromatic hydrocarbons in haze. Environ. Pollut. 231, 1601-1608. https://doi.org/10. 1016/j.envpol.2017.09.066.

Kaupp, H., McLachlan, M.S., 1999. Atmospheric particle size distributions of polychlorinated dibenzo-p-dioxins and dibenzofurans (PCDD/Fs) and polycyclic aromatic hydrocarbons (PAHs) and their implications for wet and dry deposition. Atmos. Environ. 33, 85-95. 
Kleeman, M.J., Hughes, L.S., Allen, J.O., Cass, G.R., 1999. Source contributions to the size and composition distribution of atmospheric particles: southern California in September 1996. Environ. Sci. Technol. 33, 4331-4341. https://doi.org/10.1021/ es990632p.

La Guardia, M.J., Hale, R.C., 2015. Halogenated flame-retardant concentrations in settled dust, respirable and inhalable particulates and polyurethane foam at gymnastic training facilities and residences. Environ. Int. 79, 106-114. https://doi.org/10. 1016/j.envint.2015.02.014.

Lao, J.Y., Xie, S.Y., Wu, C.C., Bao, L.J., Tao, S., Zeng, E.Y., 2018. Importance of dermal absorption of polycyclic aromatic hydrocarbons derived from barbecue fumes. Environ. Sci. Technol. 52, 330-8338. https://doi.org/10.1021/acs.est.8b01689.

Lee, S.J., Ale, D., Chang, Y.S., Oh, J.E., Shin, S.K., 2008. Seasonal and particle size-dependent variations in gas/particle partitioning of PCDD/Fs. Environ. Pollut. 153, 215-222. https://doi.org/10.1016/j.envpol.2007.07.026.

Li, Y.F., Jia, H.L., 2014. Prediction of gas/particle partition quotients of polybrominated diphenyl ethers (PBDEs) in north temperate zone air: an empirical approach. Ecotox. Environ. Safe. 108, 65-71. https://doi.org/10.1016/j.ecoenv.2014.05.028.

Li, G., Sun, H., Zhang, Z., An, T., Hu, J., 2013. Distribution profile, health risk and elimination of model atmospheric SVOCs associated with a typical municipal garbage compressing station in Guangzhou, South China. Atmos. Environ. 76, 173-180. https://doi.org/10.1016/j.atmosenv.2012.06.027.

Li, Y.F., Ma, W.L., Yang, M., 2015. Prediction of gas/particle partitioning of polybrominated diphenyl ethers (PBDEs) in global air: a theoretical study. Atmos. Chem. Phys. 15, 1669-1681. https://doi.org/10.5194/acp-15-1669-2015.

Li, W.L., Huo, C.Y., Liu, L.Y., Song, W.W., Zhang, Z.F., Ma, W.L., Qiao, L.N., Li, Y.F., 2016a. Multi-year air monitoring of legacy and current-use brominated flame retardants in an urban center in northeastern China. Sci. Total Environ. 571, 633-642. https://doi.org/10.1016/j.scitotenv.2016.07.031.

Li, W.L., Liu, L.Y., Song, W.W., Zhang, Z.F., Qiao, L.N., Ma, W.L., Li, Y.F., 2016b. Fiveyear trends of selected halogenated flame retardants in the atmosphere of Northeast China. Sci. Total Environ. 539, 286-293. https://doi.org/10.1016/j.scitotenv.2015. 09.001.

Li, Y.F., Qiao, L.N., Ren, N.Q., Sverko, E., Mackay, D., Macdonald, R.W., 2017. Decabrominated diphenyl ethers (BDE-209) in Chinese and global air: levels, gas/ particle partitioning, and long-range transport: is long-range transport of BDE-209 really governed by the movement of particles? Environ. Sci. Technol. 51, 1035-1042. https://doi.org/10.1021/acs.est.6b05395.

Liu, R., Ma, S., Li, G., Yu, Y., An, T., 2019. Comparing pollution patterns and human exposure to atmospheric PBDEs and PCBs emitted from different e-waste dismantling processes. J. Hazard. Mater. 369, 142-149. https://doi.org/10.1016/j.jhazmat.2019. 02.029 .

Lohmann, R., Harner, T., Thomas, G.O., Jones, K.C., 2000. A comparative study of the gas-particle partitioning of PCDD/Fs, PCBs, and PAHs. Environ. Sci. Technol. 34, 4943-4951. https://doi.org/10.1021/es9913232.

Luo, P., Ni, H.G., Bao, L.J., Li, S.M., Zeng, E.Y., 2014. Size Distribution of airborne particle-bound polybrominated diphenyl ethers and its implications for dry and wet deposition. Environ. Sci. Technol. 48, 13793-13799. https://doi.org/10.1021/ es5042018.

Lyu, Y., Xu, T., Li, X., Cheng, T., Yang, X., Sun, X., Chen, J., 2016. Size distribution of particle-associated polybrominated diphenyl ethers (PBDEs) and their implications for health. Atmos. Meas. Tech. 9, 1025-1037. https://doi.org/10.5194/amt-9-10252016.

Mandalakis, M., Besis, A., Stephanou, E.G., 2009. Particle-size distribution and gas/particle partitioning of atmospheric polybrominated diphenyl ethers in urban areas of Greece. Environ. Pollut. 157, 1227-1233. https://doi.org/10.1016/j.envpol.2008.12. 010 .

Offenberg, J.H., Baker, J.E., 1999. Aerosol size distributions of polycyclic aromatic hydrocarbons in urban and over water atmospheres. Environ. Sci. Technol. 33, 3324-3331. https://doi.org/10.1021/es990089c.

Offenberg, J.H., Baker, J.E., 2000. Aerosol size distributions of elemental and organic carbon in urban and over-water atmospheres. Atmos. Environ. 34, 1509-1517. https://doi.org/10.1016/s1352-2310(99)00412-4.

Offenberg, J.H., Baker, J.E., 2002. The influence of aerosol size and organic carbon content on gas/particle partitioning of polycyclic aromatic hydrocarbons (PAHs). Atmos. Environ. 36, 1205-1220. https://doi.org/10.1016/s1352-2310(01)00427-7.

Okonski, K., Degrendele, C., Melymuk, L., Landlova, L., Kukucka, P., Vojta, S., Kohoutek, J., Cupr, P., Klanova, J., 2014. Particle size distribution of halogenated flame retardants and implications for atmospheric deposition and transport. Environ. Sci. Technol. 48, 14426-14434. https://doi.org/10.1021/es5044547.

Oliveira, C., Martins, N., Tavares, J., Pio, C., Cerqueira, M., Matos, M., Silva, H., Oliveira,
C., Camoes, F., 2011. Size distribution of polycyclic aromatic hydrocarbons in a roadway tunnel in Lisbon. Portugal. Chemosphere 83, 1588-1596. https://doi.org/ 10.1016/j.chemosphere.2011.01.011.

Pan, I.J., Daniels, J.L., Goldman, B.D., Herring, A.H., Siega-Riz, A.M., Rogan, W.J., 2009. Lactational exposure to polychlorinated biphenyls, dichlorodiphenyltrichloroethane, and dichlorodiphenyldichloroethylene and infant neurodevelopment: an analysis of the pregnancy, infection, and nutrition babies study. Environ. Health Perspect. 117, 488-494. https://doi.org/10.1289/ehp.0800063.

Pankow, J.F., 1987. Review and comparative analysis of the theories on partitioning between the gas and aerosol particulate phases in the atmosphere. Atmos. Environ. 21, 2275-2283. https://doi.org/10.1016/0004-6981(87)90363-5.

Pankow, J.F., 1991. Common y-intercept and Single Compound Regressions of Gas-particle Partitioning Data Vs 1/T Atmospheric Environment 25A. pp. 2229-2239. https://doi.org/10.1016/0960-1686(91)90098-R.

Qi, H., Li, W.L., Liu, L.Y., Song, W.W., Ma, W.L., Li, Y.F., 2014. Brominated flame retardants in the urban atmosphere of Northeast China: concentrations, temperature dependence and gas-particle partitioning. Sci. Total Environ. 491, 60-66. https://doi. org/10.1016/j.scitotenv.2014.03.002.

Qiao, L.N., Zhang, Z.F., Liu, L.Y., Song, W.W., Ma, W.L., Zhu, N.Z., Li, Y.F., 2019 Measurement and modeling the gas/particle partitioning of organochlorine pesticides (OCPs) in atmosphere at low temperatures. Sci. Total Environ. 667, 318-324. https:// doi.org/10.1016/j.scitotenv.2019.02.347.

Su, P.H., Tomy, G.T., Hou, C.Y., Yin, F., Feng, D.L., Ding, Y.S., Li, Y.F., 2018. Gas/particle partitioning, particle-size distribution of atmospheric polybrominated diphenyl ethers in southeast Shanghai rural area and size-resolved predicting model. Chemosphere 197, 251-261. https://doi.org/10.1016/j.chemosphere.2018.01.005.

Venkataraman, C., Thomas, S., Kulkarni, P., 1999. Size distributions of polycyclic aromatic hydrocarbons - Gas/particle partitioning to urban aerosols. J. Aerosol Sci. 30, 759-770. https://doi.org/10.1016/s0021-8502(98)00761-7.

Wang, P., Li, Y., Zhang, Q., Yang, Q., Zhang, L., Liu, F., Fu, J., Meng, W., Wang, D., Sun, H., Zheng, S., Hao, Y., Liang, Y., Jiang, G., 2017. Three-year monitoring of atmospheric PCBs and PBDEs at the Chinese Great Wall Station, West Antarctica: levels, chiral signature, environmental behaviors and source implication. Atmos. Environ. 150, 407-416. https://doi.org/10.1016/j.atmosenv.2016.11.036.

Wang, S., Romanak, K.A., Stubbings, W.A., Arrandale, V.H., Hendryx, M., Diamond, M.L., Salamova, A., Venier, M., 2019. Silicone wristbands integrate dermal and inhalation exposures to semi-volatile organic compounds (SVOCs). Environ. Int. 132. https:// doi.org/10.1016/j.envint.2019.105104.

Weschler, C.J., Beko, G., Koch, H.M., Salthammer, T., Schripp, T., Toftum, J., Clausen, G., 2015. Transdermal uptake of diethyl phthalate and di(n-butyl) phthalate directly from air: experimental verification. Environ. Health Perspect. 123, 928-934. https:// doi.org/10.1289/ehp.1409151.

Yamasaki, H., Kuwata, K., Miyamoto, H., 1982. Effects of ambient temperature on aspects of airborne polycyclic aromatic hydrocarbons. Environ. Sci. Technol. 16, 189-194.

Yang, M., Li, Y.F., Qiao, L.N., Zhang, X.M., 2018. Estimating subcooled liquid vapor pressures and octanol-air partition coefficients of polybrominated diphenyl ethers and their temperature dependence. Sci. Total Environ. 628-629, 329-337. https:// doi.org/10.1016/j.scitotenv.2018.02.054.

Yu, H., Yu, J.Z., 2009. Modal characteristics of elemental and organic carbon in an urban location in Guangzhou. China. Aerosol. Sci. Tech. 43, 1108-1118. https://doi.org/10. 1080/02786820903196878.

Yu, H., Yu, J.Z., 2012. Polycyclic aromatic hydrocarbons in urban atmosphere of Guangzhou, China: size distribution characteristics and size-resolved gas-particle partitioning. Atmos. Environ. 54, 194-200. https://doi.org/10.1016/j.atmosenv. 2012.02 .033 .

Zhang, L.M., Gong, S.L., Padro, J., Barrie, L., 2001. A size-segregated particle dry deposition scheme for an atmospheric aerosol module. Atmos. Environ. 35, 549-560. https://doi.org/10.1016/s1352-2310(00)00326-5.

Zhang, B.Z., Guan, Y.F., Li, S.M., Zeng, E.Y., 2009. Occurrence of polybrominated diphenyl ethers in air and precipitation of the pearl river delta, south China: annual washout ratios and depositional rates. Environ. Sci. Technol. 43, 9142-9147. https:// doi.org/10.1021/es901961x.

Zhang, B.Z., Zhang, K., Li, S.M., Wong, C.S., Zeng, E.Y., 2012. Size-dependent dry deposition of airborne polybrominated diphenyl ethers in urban Guangzhou. China. Environ. Sci. Technol. 46, 7207-7214. https://doi.org/10.1021/es300944a.

Zhang, J., Li, J., Wang, P., Chen, G., Mendola, P., Sherman, S., Ying, Q., 2017. Estimating population exposure to ambient polycyclic aromatic hydrocarbon in the United States - Part I: model development and evaluation. Environ. Int. 99, 263-274. https://doi. org/10.1016/j.envint.2016.12.002. 